\title{
Escisión de un fibroma de células gigantes con láser de diodo: Informe de un caso
}

\section{Excision of a giant cell fibroma with Diodo's Laser: Report of case}

Ardila Medina $\mathrm{CM}^{*}$, Guzmán Zuluaga IC**

\section{RESUMEN}

Este artículo informa un caso de un fibroma gigantocelular localizado en tejido gingival y mucosa oral. Microscópicamente, la lesión se caracterizó por proliferación de fibras colágenas y fibroblastos gigantes, que se disponían en forma densa e irregular. Además, la superficie de la lesión estaba revestida por epitelio con cambios de hiperqueratosis. Se realizó escisión del fibroma con láser de diodo.

Palabras clave: Mucosa oral, patología, láser.

\section{SUMMARY}

This article reports a case of giant cell fibroma located in the gingival tissue and oral mucosa. Microscopically, the lesion was characterized by proliferation of collagen fibers and giant fibroblast, irregular and densely arranged. Beside, the surface was covered by epithelium with hiperqueratosis changes. The excision was done with Diodo's Laser.

Key words: Oral mucosa, pathology, laser.

Fecha de recepción: 5 de marzo de 2009.

Aceptado para publicación: 11 de marzo de 2009.

* Profesor Asistente Universidad de Antioquía. Miembro Junta Directiva Asociación Colombiana de Periodoncia y Oseointegración.

** Periodoncista Universidad de Chile. Profesora Universidad de Antioquía.

Ardila Medina CM, Guzmán Zuluaga IC. Escisión de un fibroma de células gigantes con láser de diodo: Informe de un caso. Av. Odontoestomatol 2010; 26 (3): 161-164.

\section{INTRODUCCIÓN}

El término fibroma de células gigantes (FCG) fue acuñado en 1974 por Weathers y Callihan para describir un grupo de lesiones fibrosas benignas que habían sido preliminarmente diagnosticadas como una variedad de lesiones que incluían fibromas irritativos y papilomas (1). Histológicamente, se caracteriza por la presencia de células estrelladas, mononu- cleares y multinucleares. En la evaluación de 108 casos (1), la lesión se observó en personas jóvenes localizándose con mayor frecuencia en la encía. Por el contrario, las hiperplasias fibrosas se encontraron, más a menudo, en la mucosa bucal de personas mayores (1).

Houston (2), revisó 464 casos y corroboró los resultados de Weathers y Callihan (1), encontrando dife- 
rencias mínimas. Bakos (3), igualmente publicó un informe de 116 casos, encontrando mayor prevalencia en pacientes mayores.

Se ha cuestionado si el FCG debe considerarse como una entidad separada, ya que diferentes lesiones fibrosas de la piel y de las mucosas contienen células multinucleadas y estrelladas $(4,5)$. En un estudio realizado en 1550 hiperplasias fibrosas orales (6), se demostró que el $5 \%$ de las lesiones se caracterizaban por un predominio de células multinucleadas y estrelladas, mientras que el $31 \%$ de las fibromatosis gingivales contenían las mismas características mencionadas anteriormente.

En una investigación realizada en Suecia (7), en donde se evaluaron 150 lesiones hiperplásicas de la encía y la mucosa alveolar, no se encontraron FCG, sugiriéndose poca frecuencia en ese país, comparado con otras regiones del mundo.

\section{CASO CLÍNICO}

Una paciente de sexo femenino, 45 años de edad, fue remitida por lesión localizada en los incisivos inferiores izquierdos, en la encía interproximal y en la encía y mucosa oral de la superficie lingual (Fig. 1). La patología presentaba más o menos un mes de evolución y la paciente describió un crecimien-

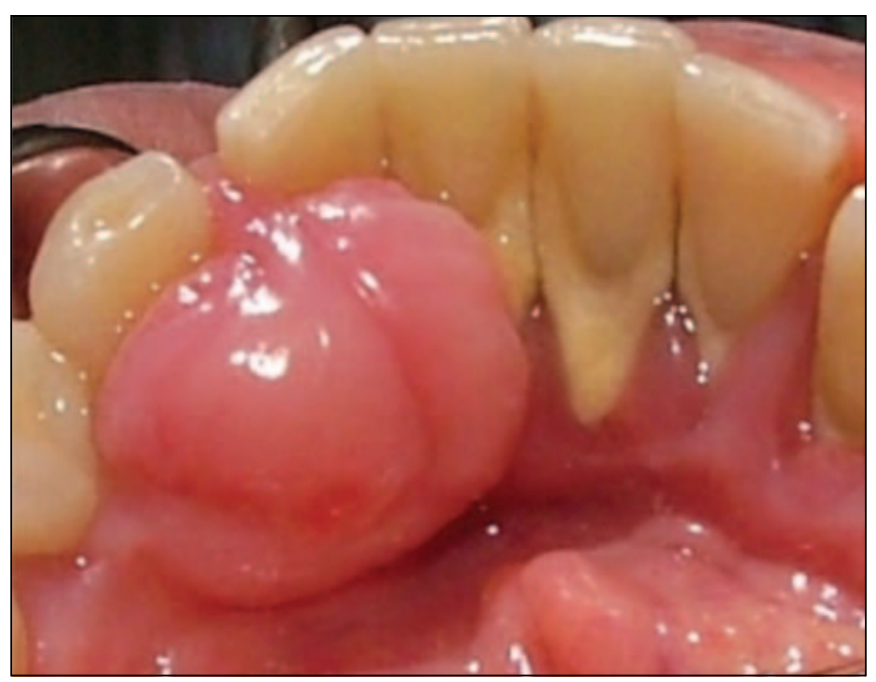

Fig.1. Fibroma de células gigantes. to progresivo, no doloroso de la encía y la mucosa de esa zona. En el examen clínico, se observó una lesión pediculada de aproximadamente un centímetro por un centímetro, de forma redondeada y color rosado. Se evidenció presencia de abundantes cálculos supragingivales y subgingivales en el área. Se observó además, inflamación marcada de la papila interdental. Al examen radiográfico no se notó ninguna alteración de importancia. La paciente no presentaba alteración sistémica alguna ni linfadenopatías y no informó ingestión de medicamentos.

Se realizó terapia mecánica periodontal con el fin de eliminar todos los cálculos presentes y se evaluó a la semana siguiente, observándose una disminución del tamaño de la lesión. Una semana después, fue intervenida realizándose una escisión de la patología con láser de diodo (Fig. 2). En la figura 3 se observa la escisión completa de la lesión.

Una biopsia de la patología fue enviada al laboratorio para realizarle análisis histopatológico. La descripción microscópica del informe concluyó que se trataba de una lesión constituida por proliferación de fibras colágenas y fibroblastos gigantes, que se disponían en forma densa e irregular, con una superficie revestida por epitelio plano estratificado con cambios de hiperqueratosis. El diagnóstico definitivo fue fibroma de células gigantes.

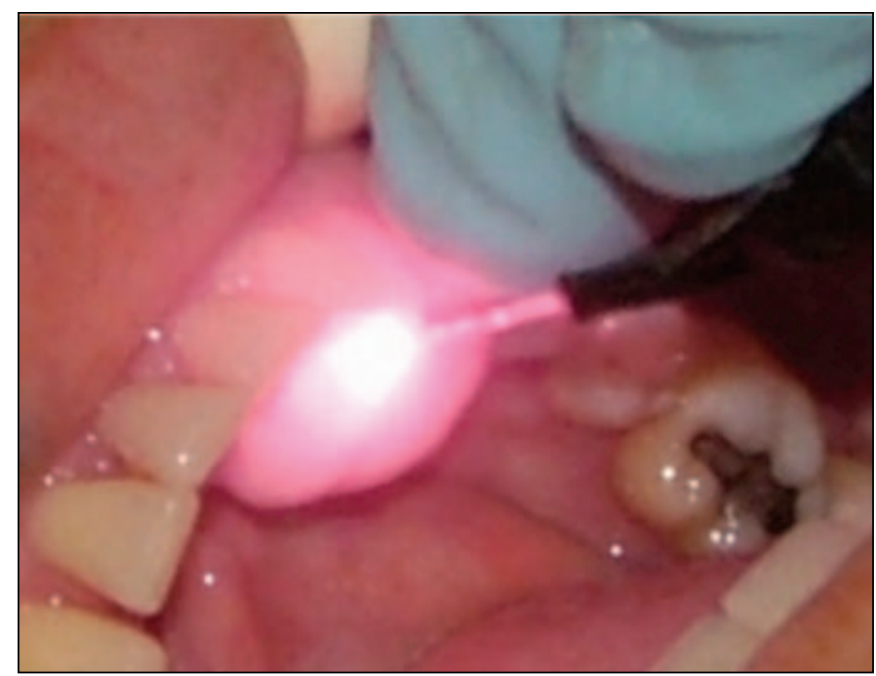

Fig. 2. Escisión de la lesión con láser de diodo 


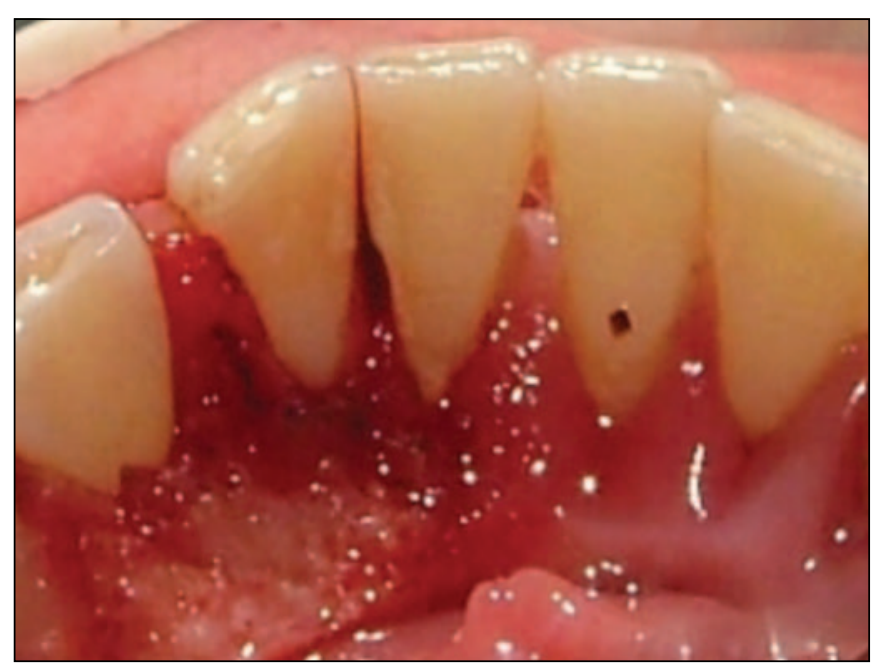

Fig. 3. Escisión de la patología.

\section{DISCUSIÓN}

Se ha observado en mujeres un predominio leve de la frecuencia del FCG $(2,3)$, mientras que otros estudios no muestran predilección por algún género $(1,6,8)$. De tal forma, esta patología no presenta la misma prevalencia por el sexo femenino (2:1), como ocurre en otras lesiones fibrosas $(1,6,9)$.

El FCG ocurre más a menudo en personas jóvenes localizándose principalmente en la encía $(1,3,6)$. Se ha encontrado una mayor prevalencia entre los $20 \mathrm{y}$ 30 años de edad $(1,2,6,8)$. Sin embargo, otros estudios (3, 9), encontraron mayor incidencia en personas mayores de 50 años. En contraste al FCG, diferentes autores corroboran que las hiperplasias más comunes (hiperplasias fibrosas, hiperplasias fibroepiteliales, fibromas) son más frecuentes en sujetos mayores de 50 años y su localización más asidua es en la mucosa oral $(1,6,9)$.

El FCG localizado en la encía y mucosa lingual, de una mujer de 45 años presentado en este artículo, sigue los parámetros informados en la literatura en cuanto a su localización en la encía, pero no coincide con el grupo de edad en el que se presenta con mayor frecuencia. Las características histopatológicas, también coinciden con los hallazgos encontrados en otros estudios, donde se observan igualmente células gigantes multinucleadas.
Considerando el origen de las células tumorales, se sugiere que pueden ser melanocitos (1). La extensión citoplasmática dendrítica de células largas, la presencia de melanina, y su número aumentado cerca del epitelio, insinúa una derivación melanocítica $(1,2)$. Sin embargo, el resultado negativo a la tinción para proteína S-100 no confirma esta sugerencia ni la de la posible relación con células de Langerhans (8). Las tinciones negativas para neutrofilamentos y para proteínas S-100, indican que las células no son de origen nervioso periférico $(3,8,9)$. Las células son negativas para factor VIII y lecitina (no hay relación con células endoteliales), lisozimas (no hay relación con células gigantes de tejido de granulación) y citoqueratinas (no hay relación con células epiteliales escamosas) (8). La pigmentación positiva para vimentina indica que las células estrelladas son de origen fibroblástico (810). Un estudio ultraestructural, ha afirmado que las células son fibroblastos inusuales (5). Sin embargo, Regezi (8), encontró resultados positivos para antiquimotrisina y para HLA-DR, proponiendo que las células provienen de células mesenquimales primitivas capaces de diferenciación macrófaga y fibroblástica. Varias lesiones fibrosas de la piel y de la mucosa contienen células estrelladas y multinucleadas de presumible origen fibroblástico $(5,6,9,10)$. Esto permite concluir que la presencia de este tipo de células no es exclusiva del FCG, y por lo tanto las lesiones son probablemente de tipo reactivo, mejor que verdaderos neoplasias.

\section{BIBLIOGRAFÍA}

1. Weathers DR, Callihan MD. Giant cell fibroma. Oral Surg Oral Med Oral Pathol 1974;37:37484.

2. Houston GD. The giant cell fibroma: a review of 464 cases. Oral Surg Oral Med Oral Pathol 1982; 53:582-7.

3. Bakos LH. The giant cell fibroma: a review of 116 cases. Ann Dent 1992;5:32-5.

4. Lukes SM, Kuhnert J, Mangels MA. Identification of a giant cell fibroma. J Dent Hyg 2005 Summer; 79:9. 
5. Regezi JA, Zarbo RJ, Tomich CE, Lloyd RV, Coutney RM, Crissman JD. Immunoprofile of benign and malignant fibro histiocytic tumors. J Oral Pathol 1987; 16:260-5.

6. Reibel J. Oral fibrous hyperplasias containing stellate and multinucleated cells. Scand J Dent Res 1982;90:217-26.

7. Anneroth G, Sigurdson Á. Hyperplastic lesions of the gingiva and alveolar mucosa. Acta Odontol Scand 1983;41:75-86.

8. Regezi JA, Courtney RM, Kerr DA. Fibrous lesions of skin and mucous membranes which contain stellate and multinucleated cells. Oral Surg Oral Med Oral Pathol 1975;39:605-14.
9. Torres-Domingo S, Bagan JV, Jiménez Y, Poveda R, Murillo J, Díaz JM, et al. Benign tumors of the oral mucosa: a study of 300 patients. Med Oral Patol Oral Cir Bucal 2008;13:E161-6.

10. Bengt C, Magnusson R. The giant cell fibroma. A review of 103 cases with inmunohistochemical findings. Acta Odontol Scand 1995;53:293-6.

\section{CORRESPONDENCIA}

Carlos Martín Ardila Medina

Carrera 47 No. 20 sur 46

Envigado Antioquía Colombia

57(4) 3348122

cmartin@odontologia.udea.edu.co 